\title{
Cone-beam dental computerize tomography for evaluating changes of aging in the dimensions central superior incisor root canals
}

\author{
Sadullah Kaya ${ }^{1}$, Ozkan Adiguzel ${ }^{1}$, Izzet Yavuz ${ }^{2}$, Emin-Caner Tumen ${ }^{3}$, Zeki Akkus ${ }^{4}$
}

${ }^{1}$ Assist. Prof. Dr. Dicle University Faculty of Dentistry, Department of Operative Dentistry, and Endodontics, Diyarbakir/Turkey

${ }^{2}$ Assoc. Prof. Dr. Dicle University Faculty of Dentistry, Department of Pediatric Dentistry, Diyarbakir/Turkey

${ }^{3}$ Assist. Prof. Dr. Dicle University Faculty of Dentistry, Department of Pediatric Dentistry, Diyarbakir/Turkey

${ }^{4}$ Assoc. Prof. Dr. Dicle University Faculty of Medicine, Department of Statistic, Diyarbakir/Turkey

Correspondence:

Dicle University Faculty of Dentistry,

Department of Operative Dentistry and Endodontics,

21280 Diyarbakir/Turkey

sadullahkaya@hotmail.com

Received: 05/03/2010

Accepted: $31 / 05 / 2010$
Kaya S, Adiguzel O, Yavuz I, Tumen EC, Akkus Z. Cone-beam dental computerize tomography for evaluating changes of aging in the dimensions central superior incisor root canals. Med Oral Patol Oral Cir Bucal. 2011 May 1;16 (3):e463-6.

http://www.medicinaoral.com/medoralfree01/v16i3/medoralv16i3p463.pdf

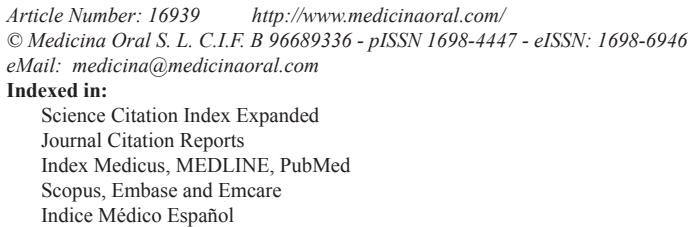

\begin{abstract}
Objectives: Cone-beam dental computerize tomography (CBCT), a noninvasive imaging method, was used to image the pulp-dentin complex. Pulp changes histologically with aging. While many studies have investigated the histological changes in pulp, few studies have focused on the changes in the shape of the root canals. This study evaluated the changes in the root canals with aging of central superior teeth using CBCT.

Study Design: The study examined 100 non-carious maxillary central teeth. These teeth were divided into five groups according to the age of the patients: Group A:15-24, Group B: 25-34, Group C: 35-44, Group D: $45-54$ and Group E: 55 years and older. CBCT was used to determine root length, and pulp width at the cervical, apical 1/2, and apical 1/3.

Results: On comparing the groups using one-way analysis of variance (ANOVA), the root length did not differ (P $>$ 0.05 ), while the pulp width at the cervical, apical $1 / 2$, and apical $1 / 3$ differed between the groups $(\mathrm{P}<0.001)$.

Conclusions: The pulp length did not change with aging, while the pulp width did change. CBCT can be used to determine the precise root length and width, to prevent iatrogenic exposure of the apex, complementing existing methods. This will improve the prediction of the prognosis of root canal treatment.
\end{abstract}

Key words: Aging, pulp dimensions, cone beam computed tomography.

\section{Introduction}

Population surveys indicate that increasing numbers of adults are retaining teeth to old age (1). In many cases, the pulp width and length in older adults is affected by dental disease, such as caries, and tooth surface loss, with a pathological or physiological etiology.

At older ages, the jaws, periodontal tissues, oral mucosa, salivary glands, and even the components of teeth change markedly. These changes affect the enamel, dentine, and pulp tissues. In adolescence, the pulp chamber is wide, and the pulp tissue is rich in vessels, and is characterized as young connective tissue. With aging, the volumes of the pulp chamber and root canal decrease and they may become completely calcified with secondary dentine (2).

It is unclear whether the fibrosis of old pulp is the result 
of the continuous formation of collagenous fibers during aging, a response to external environmental factors, or a relative increase because of the loss of pulpal area (3).

Radiography has an important place in dentistry. Since Roentgen discovered X-rays in 1895 and Kels promoted their use in dentistry, diagnosis from radiographic images has been widely used in endodontics. In most treatments, however, a two-dimensional evaluation using conventional radiographs of the teeth and jaws may not always be sufficient to make a diagnosis. Cone-beam dental volumetric tomography (CBCT) is an imageacquisition technique, based on a cone-shaped X-ray beam. The apparatus rotates once around the patient, producing a series of three-dimensional (3D) images. With CBCT, it is possible to obtain 3D images of the teeth and jaws that correspond to the actual dimensions (4). Thus, CBCT is a great aid in dentistry. Nevertheless, there are no studies that have examined its advantages over conventional radiographs about dimensional root changes.

Dedicated cone beam tomography scanners for dentistry pioneered in the late 1990s independently by Arai et al. (5) in Japan and Mozzo et al. (6) in Italy. Since then, many dental researchers have taken interest in this new imaging technique (7). Two studies have shown that CBCT can be applied clinically for measuring the root canals, identifying root canals, and anatomical variation, evaluating root fractures and resorption, and planning treatment $(8,9)$

The aim of this study was to evaluate changes in the dimensions of central superior incisors root canals with aging using CBCT images, and the utility of CBCT for measuring pulp length during root canal treatment.

\section{Materials and Methods}

This study was conducted at the Dicle University faculty of dentistry department of operative dentistry and endodontics. We didn't get ethical approval or consent from patients to do this due to this study is retrospective, study conducted on CBCT images of patients which were have taken different dental aims.

Cone-beam dental volumetric tomography (I-Cat, Imaging Sciences International, Hatfield, PA, USA) was used to take images of maxilla-facial area at a setting of $120 \mathrm{kVp}$ and 3-7 mA. Images were obtained within $10 \mathrm{~s}$ (the actual exposure time was $9 \mathrm{~s}$ ). Each scan involved a number of separate, small, individual exposures (up to 440 frames) taken over $360^{\circ}$, with a voxel size of $0.300 \mathrm{~mm}$.

This study examined 100 non-carious, non-restored, and non traumatized maxillary central teeth. The teeth were divided into five groups according to the age of the patient:

Group A: 15-24 among ages
Group B: 25-34 among ages

Group C: 35-44 among ages

Group D: 45-54 among ages and

Group E: 55 years and older.

All of measurements made by the same person. After taking the CBCT images, the roots of the teeth were measured in sagittal sections (Fig. 1), including the root length, and pulp width in the cervical, apical $1 / 2$, and apical 1/3 (Fig. 2) by I-cat software, version 1.6.2.0 (i-CAT Imaging Sciences International, Hatfield, $\mathrm{Pa}$ USA).

Evaluation of results among groups made by One way ANOVA test. The post hoc Tamhane test used for evaluation of measurements which have got from cervical area among groups. The Tukey HSD test used for evaluation of apical $1 / 2$ and apical $1 / 3$ area among groups. Evaluations of all statistical data made by SPSS 10.0 (SPSS for Windows, release 10.0.0, Chicago, IL) computer program.

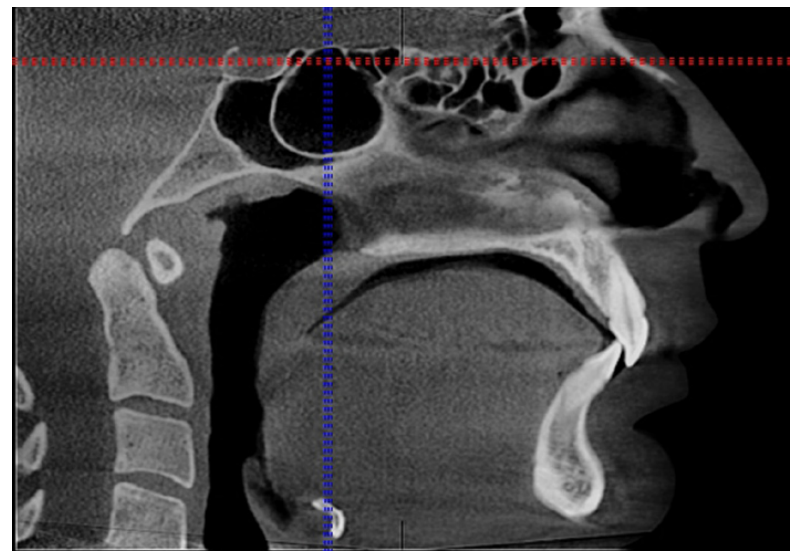

Fig. 1. Sagittal section.

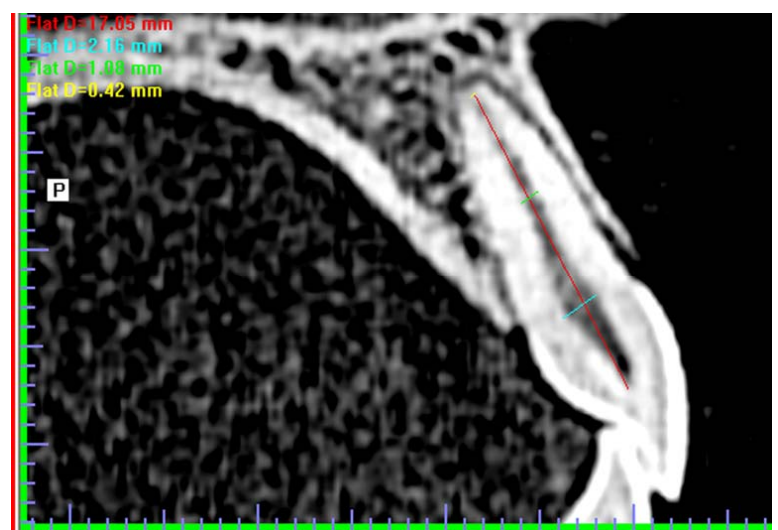

Fig. 2. Sample measurement of the root length and pulp width at the cervical, apical 1/2 and apical 1/3. 


\section{Results}

Measurements which gathered from samples obtained by the same person. Evaluation of randomly selected 20 teeth measurements in terms of error calculation made again after the 10 days. As a result of statistical evaluation there weren't any differentiation among results $(\mathrm{p}>0.05)$.

The mean and standard deviation measurements of the 100 teeth are summarized in (Table 1). There was no statistical difference in pulp length among the all ages groups ( $\mathrm{p}>0.05$ ).

There was statistical difference in cervical length among the all age groups. $(\mathrm{p}<0.001)$ The groups were then compared in pairs using the post hoc (multiple comparison) Tamhane test. There was no statistical difference in groups (A-B, C-D and D-E) about cervical measurements $(\mathrm{p}>0.05)$, while there was statistical difference in all of other groups (Table 2).

There was statistical difference in apical $1 / 2$ width among the all ages groups $(p<0.001)$. The Tukey HSD test was used to compare the apical $1 / 2$ measurements between pairs of groups. There was no statistical difference between D-E according to the multiple comparison about apical $1 / 2$ measurements ( $p>0.05$ ), while there was statistical difference in all of other groups (Table 2).

There was statistical difference in apical $1 / 3$ width among the all ages groups $(\mathrm{p}<0.001)$. The Tukey HSD test was used to compare the apical $1 / 3$ measurements between pairs of groups. There was no statistical difference among A-B, B-C and D-E according to the multiple comparison about apical $1 / 3$ measurements ( $p>0.05$ ), while there was statistical difference in all of other groups (Table 2).
Table 2. Multiple comparison for all groups about cervical, Apical 1/2 and Apical 1/3.

\begin{tabular}{|c|c|c|c|c|c|c|}
\hline & Groups & $\mathbf{A}$ & B & C & D & $\mathbf{E}$ \\
\hline \multirow{5}{*}{$\begin{array}{l}\mathbf{C} \\
\mathbf{E} \\
\mathbf{R} \\
\mathbf{V} \\
\mathbf{I} \\
\mathbf{C} \\
\mathbf{A} \\
\mathbf{L}\end{array}$} & $\mathbf{E}$ & $* * *$ & $* * *$ & $* *$ & n.s. & \\
\hline & D & $* * *$ & $* * *$ & n.s. & & \\
\hline & $\mathrm{C}$ & $* *$ & $*$ & & & \\
\hline & B & n.s. & & & & \\
\hline & $\mathbf{A}$ & & & & & \\
\hline \multirow{3}{*}{$1 / 2$} & & & & & & \\
\hline & & $\mathbf{A}$ & B & C & D & $\mathbf{E}$ \\
\hline & $\mathbf{E}$ & $* * *$ & $* * *$ & $* *$ & n.s. & \\
\hline \multirow{4}{*}{$\begin{array}{l}\text { A } \\
\mathbf{P} \\
\mathbf{I} \\
\mathbf{C} \\
\mathbf{A} \\
\mathbf{L}\end{array}$} & D & $* * *$ & $* * *$ & $*$ & & \\
\hline & $\mathrm{C}$ & $* * *$ & $*$ & & & \\
\hline & B & $* *$ & & & & \\
\hline & $\mathbf{A}$ & & & & & \\
\hline & & & & & & \\
\hline \multirow[t]{2}{*}{$1 / 3$} & & $\mathbf{A}$ & B & C & D & $\mathbf{E}$ \\
\hline & $\mathbf{E}$ & $* * *$ & $* * *$ & $* *$ & n.s. & \\
\hline \multirow{4}{*}{$\begin{array}{l}\text { A } \\
\text { P } \\
\text { I } \\
\text { C } \\
\text { A } \\
\text { L }\end{array}$} & D & $* * *$ & $* * *$ & $*$ & & \\
\hline & $\mathbf{C}$ & $* *$ & n.s. & & & \\
\hline & B & n.s. & & & & \\
\hline & $\mathbf{A}$ & & & & & \\
\hline \multicolumn{7}{|c|}{$\begin{array}{l}\text { n.s. Not Significant } \quad * \text { p }<0.0 \\
\text { Group A: } 1524 \text { among ages } \\
\text { Group B: } 2534 \text { among ages } \\
\text { Group C: } 3544 \text { among ages } \\
\text { Group D: } 4554 \text { among ages } \\
\text { Group E: } 55 \text { years and older. }\end{array}$} \\
\hline
\end{tabular}

Table 1. Mean measurements for each group as a millimeter. (SD: Standard Deviation).

\begin{tabular}{|l|c|c|c|c|c|}
\hline \multicolumn{1}{|c|}{ Measurement } & Group A (n=20) & Group B (n=20) & Group C (n=20) & Group D (n=20) & Group E (n=20) \\
\hline & Mean \pm SD & Mean \pm SD & Mea \pm SD & Mean \pm SD & Mean \pm SD \\
\hline Lenght of root & $13.3900 \pm 1.9893$ & $14.2875 \pm 2.6986$ & $12.6685 \pm 2.0911$ & $12.9875 \pm 2.0957$ & $13.7965 \pm 1.8259$ \\
\hline Pulp width at cervical & $1.8400 \pm 0.3883$ & $1.7015 \pm 0.2581$ & $1.4280 \pm 0.2946$ & $1.2535 \pm 0.2608$ & $1.0785 \pm 0.2628$ \\
\hline Pulp width in apical 1/2 & $1.2925 \pm 0.2479$ & $1.0595 \pm 0.2232$ & $0.8900 \pm 0.1796$ & $0.7060 \pm 0.1324$ & $0.6685 \pm 0.1379$ \\
\hline Pulp width in apical 1/3 & $0.5900 \pm 0.1620$ & $0.5385 \pm 0.1593$ & $0.4395 \pm 0.1291$ & $0.3100 \pm 0.0678$ & $0.3195 \pm 0.0621$ \\
\hline
\end{tabular}




\section{Discussion}

The numerical and volumetric decrease in odontoblasts may cause recession of cell extension from the dentine tubules, increase calcification, decrease in volume and pulp chamber $(10,11)$.

There is a decrease in the number of cells in the pulp and an increase in the fibrous component with age (3). Shroff pointed out that the increase in the fibrous elements that occurred in aging could simply be the result of the persistence of fibrous elements of an originally larger pulp (12). Stanley and Ranney (13) concluded that the amount of collagen did not increase in the coronal pulp tissue after the age of 20 years. This study may explain the decrease in the volume of pulp tissue we observed in teeth from patients older than 15-24 years. During the aging process, there is not only a decrease in the size of the pulp chamber, but also a loss of blood vessels and nerves. Simultaneously, the number of collagen bundles in the coronal pulp increases (3). Moreover, the pulp may lose its vitality as a result of dental trauma and this may alter the volume of the pulp chamber and root canal.

The use of CBCT may help to prevent accidental pulp exposure in clinical practice (14).

According to Patel et al. (15) the roots of the posterior maxillary teeth and their periapical tissues can be visualized separately and in all three orthogonal planes without superimposition of the overlying zygomatic buttress, alveolar bone, and adjacent roots. Three-dimensional imaging allows visualization of the anatomical relationships of the root apices to important neighboring anatomical structures, such as the inferior dental canal and mental foramen.

Root morphology can be visualized in three dimensions, as can the number of root canals and whether they converge or diverge from each other. Unidentified (and untreated) root canals in root-filled teeth may be identified using axial slices, which are not readily identifiable with periapical radiographs, even if taken at different angles. The true size, location, and extent of periapical disease should be appreciated, while the actual root with which the lesion is associated should be identifiable with confidence (15).

We believe that CBCT clearly reveals the real view of the pulp chamber for measurements due to CBCT have no magnification. However, few studies have addressed the endodontic treatment of root canals using tomography.

Previous research (16) showed that the pulp tissue decreased with aging, while the thickness of the remaining dentin increased, consistent with our results.

The dimensions of the pulp chamber are reduced by calcification, which tends to be greater at the roof of the pulp chamber and on the axial walls than on the floor of the pulp chamber (17). Using CBCT, although we found no significant between-group differences in pulp canal length, there was a significant difference in pulp canal width. The greatest decrease in pulp width was seen in the cervical and apical 1/2, especially in the 45-54 year age group. By contrast, the widest root canals were in the 15-24 year age group, in agreement with report that the pulp chamber is wide and rich in vessels in that age group (10).

\section{Conclusions}

1) It is revealed that there was no difference among age groups pulp lenght measurements, while there was difference in all of age groups about cervical, apical $1 / 2$ and apical 1/3 width measurements.

2) CBCT useful tool it supplies sensitive measurements for dental research.

\section{References}

References with links to Crossref - DOI

1. Allen PF, Whitworth JM. Endodontic considerations in the elderly. Gerodontology. 2004;21:185-94.

2. Miller WA, Karuza J. Recent clinical research in geriatric dentistry. Gerodontology. 1988;7:37-43.

3. Bernick S, Nedelman C. Effect of aging on the human pulp. J Endod. 1975;1:88-94.

4. Bernardes RA, de Moraes IG, Húngaro Duarte MA, Azevedo BC, de Azevedo JR, Bramante CM. Use of cone-beam volumetric tomography in the diagnosis of root fractures. Oral Surg Oral Med Oral Pathol Oral Radiol Endod. 2009;108:270-7.

5. Arai Y, Tammisalo E, Iwai K, Hashimoto K, Shinoda K. Development of a compact computed tomographic apparatus for dental use. Dentomaxillofac Radiol. 1999;28:245-8.

6. Mozzo P, Procacci C, Tacconi A, Martini PT, Andreis IA. A new volumetric $\mathrm{CT}$ machine for dental imaging based on the cone-beam technique: preliminary results. Eur Radiol. 1998;8:1558-64.

7. De Vos W, Casselman J, Swennen GR. Cone-beam computerized tomography $(\mathrm{CBCT})$ imaging of the oral and maxillofacial region: a systematic review of the literature. Int J Oral Maxillofac Surg. 2009;3:609-25.

8. Cohenca N, Simon JH, Roges R, Morag Y, Malfaz JM. Clinical indications for digital imaging in dento-alveolar trauma. Part 1: traumatic injuries. Dent Traumatol. 2007;23:95-104.

9. Cohenca N, Simon JH, Mathur A, Malfaz JM. Clinical indications for digital imaging in dento-alveolar trauma. Part 2: root resorption. Dent Traumatol. 2007;23:105-13.

10. Götze W, Schaller HG, Schulz R. [The correlation among pulp chamber, tooth length and tooth width in different age groups]. Dtsch Zahnarztl Z. 1989;44:47-9.

11. Iacopino AM, Wathen WF. Geriatric prosthodontics: an overview. Part II. Treatment considerations. Quintessence Int. 1993;24:353-61. 12. Shroff FR. The physiologic pathology of changes in the dental pulp. I. Senile pulp atrophy. Oral Surg Oral Med Oral Pathol. 1953;6:1455-60.

13. Stanley HR, Ranney RR. Age changes in the human dental pulp. I. The quantity of collagen. Oral Surg Oral Med Oral Pathol. 1962;15:1396-404.

14. Braz AK, Kyotoku BB, Gomes AS. In vitro tomographic image of human pulp-dentin complex: optical coherence tomography and histology. J Endod. 2009;35:1218-21.

15. Patel S, Dawood A, Ford TP, Whaites E. The potential applications of cone beam computed tomography in the management of endodontic problems. Int Endod J. 2007;40:818-30.

16. Camps J, Déjou J, Rémusat M, About I. Factors influencing pulpal response to cavity restorations. Dent Mater. 2000;16:432-40.

17. Muramatsu T, Hamano H, Ogami K, Ohta K, Inoue T, Shimono M. Reduction of osteocalcin expression in aged human dental pulp. Int Endod J. 2005;38:817-21. 